\title{
TENSIONES EN LA RELACIÓN \\ CIVIL-MILITAR \\ EN EL ECUADOR DEL SIGLO XXI
}

\author{
Dr. Fernando Bustamante *
}

\section{LAS BASES DEL SISTEMA DE RELACIONES CIVIL-MILITA- RES DE 1979}

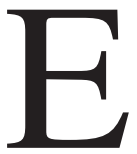

I proceso de transición democrática de fines de los años 70 y que en 1979 culminara con el retorno de gobiernos civiles elegidos supuso, asimismo, la cristalización de un esquema de relaciones entre los poderes públicos civiles y las FFAA.

Este sistema de relaciones civil-militares se institucionalizó no solo en una legislación, en un conjunto de cuerpos legales o en un reglamento, sino que también consistió en un conjunto de prácticas, hábitos y costumbres tácitamente reconocidos por los agentes centrales del sistema político y por la opinión pública. De esta manera se consolidó un régimen de relaciones civil-militares sustentado parcialmente en la Constitución escrita y en una consuetudine que no por "informal"o implícita adquiere menos fuerza o es menos imperativa para los agentes del sistema político. Este régimen al que se hace referencia, estaba sostenido en un conjunto de pilares o supuestos fundamentales. A continuación se esbozan algunos de los rasgos centrales de este régimen.

En primer término, los militares se retiran de la gestión pública o renuncian a cualquier pretensión de liderazgo explícito sobre el Estado. Al mismo tiempo, y en contrapartida, se desarrolla un conjunto de mecanismos que apunta a limitar severamente la posible "intromisión"civil en el manejo de las FFAA y de muchas áreas de la seguridad del Estado. Se intenta, ante todo, reducir y controlar las tendencias históricas de los políticos y gobernantes civiles a tratar de clientelizar a las instituciones castrenses así como buscar

* Catedrático de la Universidad San Francisco de Quito, Profesor Asociado de la Sede Académica FLACSO-Ecuador. 
la conformación de un liderazgo presidencialista subjetivo sobre los mandos militares (la traumática experiencia de los velasquismos constituye un antecedente inmediato pero no único de este interés militar por circunscribir estrechamente la influencia civil sobre los cuarteles).

De esta forma se arriba a una especie de pacto político constituyente del régimen de 1979: por un lado las FFAA se retiran de la presencia abierta en la política, y por otro lado los políticos civiles les garantizan una no injerencia en sus asuntos, una abstención civil en el manejo de las políticas de seguridad y un sustancial autogobierno castrense sobre una serie de áreas de acción que les quedan reservadas a las FFAA. Muchas de estas áreas de acción se convierten en "reductos" institucionales corporativistas e incluyen sectores de actividad que normalmente no se consideran (al menos en las democracias clásicas) temas de competencia castrense (por ejemplo: las industrias militares y las actividades empresariales de las FFAA). Las Fuerzas Armadas se reservan de manera permanente un amplio segmento de áreas de influencia y de atribuciones intocables que son la "garantía tácita" de la autonomía militar frente a una política civil siempre vista como una fuente latente de amenazas a la estabilidad de la carrera militar, a sus valores profesionales y al profesionalismo mismo. Esto último, por otra parte, es visto como consubstancial a la existencia y naturaleza moral de la nación y del estado ecuatorianos. En cierta media se presenta un tácito supuesto de que los militares entregan el gobierno a los civiles a cambio de reservarse el manejo de lo fundamental, permanente y central del Estado, lejos del barullo y agitación superficial de la política civil.

Pero el sistema de 1979 no solamente consagra una autonomía militar expansiva de tipo defensivo. Al mismo tiempo que crea una serie de reductos corporativistas con dominación castrense, sistematiza, aunque de manera sutil una vieja tradición para-constitucional ecuatoriana. el rol arbitral de las FFAA.

En efecto, los militares en Ecuador han sido vistos históricamente como el poder tutelar en última instancia. Se entiende que en caso de bloqueo del poder civil o de situaciones de ingobernabilidad producidas por los problemas inherentes al sistema de gobierno 
del país, las FFAA tienen un derecho (e incluso una obligación) de intervenir y ejercer un "poder moderador". En realidad, en la tradición ecuatoriana y en los hábitos paraconstitucionales, existen reglas más o menos claras que delimitan cuándo debe darse esta intervención y qué alcances debe tener. Estas intervenciones de tipo "arbitral"dan a las FFAA un papel crucial pero subordinado. Las intervenciones militares deben, ante todo, crear las condiciones para una renegociación de los términos del pacto político entre las elites. Se trata pues de intervenciones que son homólogas a lo que en un régimen parlamentarista sería una "disolución presidencial" del parlamento.

Esta forma de intervención militar, en ningún caso autoriza a las FFAA a intentar imponer por sí mismas y por ellas mismas un proyecto de Estado de largo plazo o generado por fuera del consentimiento de las elites civiles. Se trata ante todo de ejercer un papel facilitador del desbloqueo de las relaciones intra-civiles e intra-elites amagadas por problemas inmanejables bajo los términos del acuerdo vigente hasta entonces.

Es por ello que en general, las elites civiles solo se han opuesto vigorosamente a aquellos gobiernos militares que han roto con estas reglas y que han intentado ir más allá del poder arbitral, desarrollando pretensiones "fundacionales"o de hegemonía castrense estable. Esta situación se ha dado en dos casos: a raíz del proyecto juliano de 1925 y en el período del "Nacionalismo Revolucionario"del General Guillermo Rodríguez Lara 1972-1976.

En todo caso, a partir de 1979 y por reacción tanto en contra del caudillismo civil como de la posible reaparición de mesianismos castrenses de corte fundacional, el sistema del régimen vigente consagra tanto la autonomía corporativista expansiva como (de manera tácita o soterrada, pero no por ello menos efectiva) la función tutelar y de poder "en última instancia"que ningún poder civil realmente existente puede legítimamente recabar para sí bajo el sistema constitucional ecuatoriano.

De hecho, y de manera casi abierta, la Constitución de 1998, esboza una formulación de este poder "tutelar"al entregarles la función de "garantes de la Constitución". Dado que la Constitución no 
se interpreta a sí misma, y al no definirse claramente la instancia civil cuya interpretación y aplicación los militares deben acatar, se consagra de hecho a las FFAA como intérpretes últimos de esta ley fundamental y de sus aplicaciones. De esta forma, aunque de manera soterrada, la propia Constitución les da a los militares un poder legal (y presumiblemente legítimo) de constituirse en corte final en los asuntos que comprometen la vigencia de la ley fundamental.

Esta función de tutela no aparece normalmente y de manera rutinaria en el escenario político. Las FFAA no toman parte activa ni de forma habitual en el quehacer ostensiblemente político del Estado, sin embargo, su muda presencia es un dato constitutivo de las disputas políticas, ya que todos los actores saben y consideran en sus cálculos estratégicos, que las instituciones castrenses son este dispositivo para-constitucional de última instancia. Los actores políticos se preparan y actúan con vistas a posicionarse lo mejor posible para este implícito arbitraje militar y, llegado el caso, lo demandan y exigen como parte de los deberes tutelares de las FFAA.

La intervención militar es una posibilidad latente (y no siempre percibida como amenaza) que la sociedad y los políticos contabilizan como parte de las realidades contextuales en las que se mueve la vida cívica. Esta intervención, como se ha dicho antes, no es, contrariamente a lo que podría parecer, una intervención "anómica"o extrasistémica, muy por el contrario se halla normada de manera precisa (respecto a su ocasión, procedimientos y fines aceptables) y es interna al sistema mismo, como una de sus instancias predecibles y como mecanismo funcional claramente programado.

\section{CARÁCTER DE LA INTERVENCIÓN Y DE LA AUTONOMÍA MI- LITARES}

Como se ha señalado, el sistema ecuatoriano tolera un alto nivel de participación militar no responsable (no sometida a escrutinio y fiscalización civil) en numerosas áreas no estrictamente profesionales, a menos de acuerdo a una visión "clásica"y restringida del rol castrense en las democracias modernas. 
Además, es necesario precisar bajo qué condiciones opera la tutela castrense en tiempos de excepción. Bajo estas últimas condiciones las FFAA asumen además un rol proactivo y un protagonismo arbitral, que puede incluir la toma directa (aunque provisional del poder) o una influencia visible y decisiva en la formación del nuevo gobierno civil.

A este respecto cabe señalar que las FFAA entran en acción ostensible en condiciones de crisis gubernamental, y en ese sentido llenan una función que el multipartidismo fragmentado y el presidencialismo sin autoridad de última instancia dejan suspendida en el aire (sin órgano civil decisivo y legítimo). De alguna forma esto se relaciona con lo que podríamos llamar el sistema de "soberanía truncada" que afecta al Estado ecuatoriano. Esta forma de soberanía se da cuando el poder estatal carece de un referente simbólico final no discutible: un garante sistémico en última instancia y que pueda presentarse como independiente de los propios actores políticos envueltos en las disputas contingentes. Esta función es la que cumplen los monarcas o presidentes en los sistemas parlamentarios europeos o la Corte Suprema de Justicia en Estados Unidos o el Consejo Islámico en la República Islámica de Irán, por citar solo algunos ejemplos.

En Ecuador, el derrocamiento de la monarquía absoluta, entre 1809-23, no dio pie a su reemplazo por un equivalente funcional estable de nivel nacional. En realidad, todos los gobiernos ecuatorianos tienen un carácter provisional y gozan de un poder "hasta nuevo aviso", sin una garantía intangible en última instancia. Las FFAA cumplen de facto el rol de poder soberano final y tienen el poder de "disolución" propio del depositario final de la legitimidad soberana.

El carácter trunco de la soberanía del Estado ecuatoriano se vincula a la imposibilidad de hallar un consenso práctico (por contraste con el consenso puramente abstracto de la teoría o ideología política en uso corriente) en torno al principio organizador de la república. El principio de la soberanía popular nunca ha sido tomado en serio. Hacerlo implicaría ciertos supuestos culturales fundacionales que incluso hoy en día se hallan notoriamente ausentes. Siguiendo a Tocqueville, podríamos decir que una república demo- 
crática debe fundarse en un mutuo reconocimiento de la igualdad de todos los miembros. Esta igualdad es o debe ser parte de la "religión cívica"del pueblo y no puede tolerar identidades ciudadanas construidas sobre la base de la diferencia/deferencia, de la jerarquía ontológica o de la discriminación adscriptiva.

La nación ecuatoriana, se ha construido en cambio, y precisamente, sobre la base de estos complejos político-culturales. Los actores relevantes de la política operan sobre el trasfondo de un no reconocimiento ni aceptación prácticos de la igualdad cívica. De esta forma, es imposible (en la rutina de los hechos) aceptar al "otro" como igualmente digno de gobernar y de gobernarse (el complejo absolutista de la jerarquía de las naciones: unas más civilizadas que las otras). Por otra parte, los orígenes presuntamente revolucionarios del Estado vetaban desde un inicio el recurso a formas abiertamente estamentales, absolutistas o metafísicas de fundamentación del orden público. De esta forma, el Estado ecuatoriano no puede ser ni democrático ni revertir sobre formas de "ancien regime"intolerables por razones probablemente exógenas a la voluntad o preferencias latentes de las elites fundadoras. Esto ayuda a entender porqué es necesario recurrir a las figura de las FFAA como universalidad del Estado, como última instancia legítima, levantada por encima de los partidismos o de los particularismos. En suma, como forma concreta de lo que Hegel llamaría el "espiritu universal". Esta postura requiere, pues, la segregación militar de la cotidianeidad del poder y de sus desgastes, a fin de preservar mejor su majestad implícita de poder en última instancia.

\section{ROL ESTRATÉGICO}

En la comprensión de la política militar en el Ecuador y de su problemática actual, no puede quedar fuera la consideración de su rol estratégico. En efecto, aparte del papel institucional interno y de sus importantes funciones económicas, sociales, simbólicas y políticas, el mundo castrense tiene un papel y una justificación basada en las necesidades estratégicas y geopolíticas que putativamente debe satisfacer.

Después de todo, las FFAA supuestamente existen ante todo para defender al país de amenazas externas potenciales o actuales. 
Los papeles domésticos pueden ser muy importantes, pero en definitiva deben presentarse (séanlo o no) como secundarios respecto a la función primaria de defensa de la soberanía frente a posibles enemigos foráneos.

En realidad, desde una perspectiva estrictamente funcional ambos tipos de papeles configuran la misión de las FFAA, aunque los de naturaleza interna no siempre son manifiestos o plenamente reconocidos, entendidos o vistos en su articulación con los estratégicos. De hecho, buena parte de la justificación pública del copamiento militar de ciertas áreas socio-económicas domésticas radica en su presunta vinculación con el esfuerzo de defensa nacional convencional. Incluso la acción cívica es vista, en buena medida, como una componente de las operaciones de "guerra sicológica" destinada a fortalecer moralmente el frente interno y aumentar la adhesión cívica de las poblaciones más desposeídas hacia el Estado y a sus agentes uniformados: se trata ante todo de operaciones de consolidación del frente interno frente a potenciales desafíos geopolíticos.

Dicho lo anterior, es preciso reconocer, que, casi desde sus inicios como instituciones profesionales modernas, a partir de la primera década del siglo XX, las FFAA ecuatorianas han definido su razón de ser estratégica por la necesidad de hacer frente a la amenaza peruana y prepararse para defender la soberanía frente al vecino del sur. Esta necesidad ha sido subrayada por al menos tres enfrentamientos de cierta envergadura $(1941,1981$ y 1995) y por una situación de "guerra larvada" que ha perdurado desde los inicios de la República hasta 1998.

La amenaza fronteriza ha sido el norte institucional, la razón de ser de la carrera militar, el supuesto central de la planificación estratégica y la hipótesis de conflicto preeminente durante toda la historia de las FFAA nacionales, con excepción, claro está, del último lustro transcurrido desde la firma de los acuerdos de Brasilia.

El término del conflicto con el Perú, pone fin a una época del desarrollo de las FFAA ecuatorianas como instrumento estratégico del Estado. Pone también fin a toda una concepción de la seguridad nacional y de la identidad militar. En el pasado, prácticamen- 
te el conjunto del ethos militar se hallaba permeado por el enfrentamiento con el Perú. Generación tras generación el cuerpo de oficiales había vivido en y para el conflicto con el vecino del sur. No solo el sentido del cuerpo sino que también la identidad misma de la nación han sido vistos a través del prisma proporcionado por la hipótesis de conflicto militar con el Perú. Ha podido incluso llegar a afirmarse que el Ecuador debe su existencia como Estado unitario y su capacidad de resistir sus tendencias centrífugas internas a la presencia de esta alteridad amenazante.

El fin de esta perspectiva profesional casi congénita ha planteado para los oficiales de las FFAA ecuatorianas dos preguntas que, dados los antecedentes de la cultura organizacional castrense, son casi una sola y misma pregunta: ¿cuáles deben ser el papel y las misiones futuras de las FFAA en un mañana sin guerra posible con el Perú y con fronteras definitivas y pacíficas? Y, en adelante ¿en torno a qué debe afianzarse el sentido de identidad nacional? Estas preguntas son muy cercanas para los militares ante todo por la tendencia persistente a identificar a las FFAA como el "alma"o "columna vertebral" de la nación. De esta forma el destino de las FFAA es consubstancial con el de la nación.

Nación y Fuerzas Armadas comparten una misma esencia sustantiva y se definen mutuamente de manera inextricable.

La ausencia del espectro peruano da paso al de la disolución interna del país, de la desintegración de ese mosaico socio-cultural en el que el Ecuador se redescubre a partir de los años 90. Pero, al mismo tiempo, y en un mismo movimiento, abre las puertas a la posible disolución "moral" de las FFAA, al quedar ellas desprovistas de una misión que justifique su existencia. Esta "disolución" puede concretarse por un lado en la descomposición internada derivada de la ausencia de un sentido de tarea y de un propósito institucional claramente percibido, y por otra parte del peligro de que los poderes civiles y la sociedad misma lleguen a considerar a una fuerza sin misión como más o menos superflua y, por tanto, prescindible en los términos o importancia tradicionalmente aceptados.

Así se entiende también la premura e insistencia con la cuál se busca activar amenazas sustitutivas que puedan "unir" al país de 
manera análoga a como lo hizo el peligro meridional. Detrás existe, sin duda, un acendrado pesimismo frente a los resultados de dos siglos de esfuerzos de "construcción nacional". De cierta forma se acepta que la unidad nacional no puede (aún) prescindir del "exoesqueleto"proporcionado por un peligro o amenaza externos. El desarticulado cuerpo de la nación aún resulta incapaz de sostenerse solo, en sus propios términos sin un referente agnóstico, sin una alteridad amenazante.

Ciertamente esto puede ayudar a explicar porqué súbitamente la frontera norte es "redescubierta"como fuente de amenazas y como zona de peligro. El conflicto colombiano, con el cual se ha coexistido por medio siglo, sin mayor alarma o tropiezo y de acuerdo a normas muy claras aunque tácitas de convivencia con las distintas facciones combatientes; se hace súbitamente un inminente peligro para la seguridad y la soberanía, aun cuando no existen acciones de las partes que impliquen un cambio importante en la implícita exclusión del Ecuador y de su territorio como escenario bélico. La influencia y presión de los Estados Unidos y del Plan Colombia, sin duda tienen algo que ver en este redescubrimiento del hasta ahora olvidado "frente norte", pero las necesidades institucionales y los supuestos peligros de una implosión endógena del Ecuador, hacen imperativo desarrollar una hipótesis de amenaza que es preciso hacer creíble e inminente. Por otra parte, no faltan sectores civiles que esperan tener mucho que ganar con una infusión de recursos movidos por el pánico o el oportunismo estratégico. Estos sectores civiles, aunque por otras motivaciones, contribuyen poderosamente a validar esta nueva perspectiva corporativa de las FFAA y las nuevas hipótesis de amenaza "septentrionales".

Por otra parte, el cambio de énfasis en cuanto a la fuente principal de amenazas estratégicas para el país, tiene también algunas consecuencias en términos de alianzas y de posicionamiento en el ámbito internacional.

En efecto, el conflicto con el Perú fue siempre un problema en el que el Ecuador actúo en "solitario". El cuestionamiento del Protocolo de Rio de Janeiro, así como las reclamaciones territoriales ecuatorianas, antes y después de la firma de dicho instrumento ju- 
rídico, fueron asuntos provocados unilateralmente por el Ecuador, de su exclusivo interés y movidos por dinámicas internas del propio país. En realidad, en su reclamación irredentista el Ecuador no solo actúo desde sus propias prioridades, desde su propia percepción y desde su definición de la situación, sino que lo hizo, en cierta manera, como Estado "fuera de la ley"y en contra del statu quo estratégico regional. En ese sentido el país se planteó como un "outsider" que se rehusaba acatar el orden hemisférico y las estructuras de legitimidad internacional constituidas a lo largo del siglo XX.

En cambio, y a diferencia de la situación anterior, los esfuerzos por involucrar al país en el Plan Colombia y por llevarlo a aceptar la definición del problema promocionada por Washington y Bogotá, pone al Ecuador en la perspectiva de actuar como parte de una coalición liderada por el hegemón y con fuertes probabilidades de gozar de una amplia cobertura de legitimidad internacional. La posibilidad de actuar en la frontera norte, se da en el contexto de una colaboración (y tal vez de una alianza estratégica) con Colombia y Estados Unidos y como parte del orden hemisférico. La colaboración con la vigilancia de las actividades del narcotráfico ha sido un preludio a este reposicionamiento de las FFAA del Ecuador no como instrumentos de una "rebelión"contra el orden hemisférico, sino muy por el contrario, como partes de un proyecto estratégico multilateral y legitimista (sino legítimo). Esto, sin duda, les abre a las FFAA ecuatorianas no solo la posibilidad de salir de su relativo aislamiento internacional y de su histórico "provincianismo", sino que además abre las puertas para una influencia todavía más marcada de los Estados Unidos y de otras fuerzas armadas vecinas en el desarrollo de sus capacidades y planes institucionales, así como de sus actitudes políticas y estratégicas.

Es posible pensar que la postura estratégica y las hipótesis de conflicto de las FFAA ecuatorianas con anterioridad a 1998 tuvieron una relación con la forma cómo se diseñó el sistema de relaciones civil-militares en el país. Sería posible intentar discernir de qué manera los imperativos geopolíticos y operacionales del conflicto con el Perú pusieron su impronta en la estructura de estas relaciones. 
Ciertamente, la autoconciencia de ser FFAA en conflicto fronterizo latente y la creencia de que dicho conflicto podía llegar a comprometer la existencia misma de la nación, le dio un carácter de estado de emergencia o de excepción a la vinculación civil-militar. Después de todo si el país debía hacer frente a una amenaza convencional en sus fronteras, y aun cuando las hostilidades no se materializaran, era claro que el Estado nacional debía vivir "velando las armas". Esto daba sustento a toda una institucionalidad de "emergencia", que sin embargo se hizo y se vivió como "normal".

Por ejemplo, buena parte del esfuerzo de acción cívica tuvo como trasfondo la necesidad de establecer una presencia del Estado y de sus aparatos de seguridad en zonas demográficamente marginales y débilmente incorporadas a la vida del país. El desarrollo de estas relaciones de encuadramiento luego fue extendido a todas las poblaciones que, si bien no se hallaban cerca del posible teatro de operaciones o en las fronteras disputadas, podían llegar a padecer de problemas de lealtad y constituirse en "quinta columnas"desleales o campo fértil para acciones de guerra sico-social debilitantes.

Así mismo, la historia de la penetración peruana en zonas disputadas llevó a desarrollar esfuerzos vigorosos por "nacionalizar" a las poblaciones residentes en dichas áreas. Ocupar un territorio implicaba no solo la presencia militar, sino también el desarrollo de estrechas vinculaciones de la sociedad local con el resto del país y con sus instituciones. Esta fue siempre vista como una tarea estratégica que rebasaba con mucho las posibilidades de un estado civil de "tiempos normales".

Los militares ecuatorianos desarrollaron frente a estos desafíos toda una ideología basada en la incapacidad de las elites y del Gobierno civil para cumplir las funciones de "construcción nacional" y de ocupación efectiva de las fronteras y del espacio estratégico interior. En cierta forma las FFAA nacionales se hacen eco de ideas como las de John Jonson y Lucian Pye, quienes en los años cincuenta y sesenta sostenían que los militares del Tercer Mundo podían convertirse en vanguardias de la modernización estatal en medio de un "océano de atraso" y ante la incapacidad de elites civiles sumidas en el tradicionalismo, para hacer frente a las tareas 
urgentes de la modernidad. Como lo han señalado Charles Tilly o Michael Mann entre otros, las presiones de la guerra y de la competencia estratégica han sido factores catalíticos centrales en la construcción y modernización de los estados occidentales y de sus competidores de otras partes del mundo. Los militares ecuatorianos, conciente o inconscientemente han tomado estas ideas por su cuenta y han visto su ocupación de áreas sico-sociales como parte de esa tarea pendiente que las elites civiles "atrasadas" no podían o no querían realizar. Las FFAA se han visto, así como las encargadas de preparar al país para la guerra modernizándolo e integrándolo ( "vertebrándolo"), en subsidio de una defección de las clases dominantes domésticas.

Debe, pues, verse como muy estrechamente ligada la problemática estratégica a la cuestión de las formas peculiares que en Ecuador toma el vínculo Estado-Fuerzas Armadas-Sociedad Civil. La situación de guerra latente prolongada define el campo de preocupaciones al interior del cual adquieren sentido muchas de las soluciones halladas para establecer un sistema de relación de los militares con el resto del país.

Es posible, a partir de las consideraciones anteriores, suponer que las FFAA intentarán, a su vez, reestablecer una situación estratégica externa que cumpla con ser un "equivalente funcional"al conflicto con el Perú, y que les permita proteger su inversión histórica en un sistema que les ha dado estabilidad, identidad y posición en la vida del país.

En efecto, es frecuente que un mecanismo originalmente desarrollado para cumplir con una función, se convierta en fin en sí mismo, más allá aún de la supervivencia de la necesidad que le vio nacer. Las organizaciones e instituciones desarrollan intereses creados en su propia estructura en las prácticas históricamente acumuladas. Si luego el entorno se modifica, es preciso para ellas buscar definir nuevas funciones y tareas para aquellos dispositivos originales, y ello, con frecuencia conlleva la necesidad de manipular el ambiente para obligarlo (por así decir) a revalidar la utilidad y necesidad de la organización tal como está ya constituida. Nada hace pensar que las Fuerzas Armadas ecuatorianas vayan a ser ajenas a esta lógica. 


\section{LA RECIENTE CRISIS DEL PROFESIONALISMO MILITAR}

A pesar de los esfuerzos posteriores a 1998, en el sentido de reestructurar las misiones de las FFAA en términos compatibles con la reproducción de su función y de su inserción sistémica clásica, existen razones para temer que el modelo profesional instaurado a partir de 1941 se halla en serio peligro.

Como se señaló al final de la sección precedente, el fin del conflicto con el Perú, amenazaba con socavar las bases de sustentación y de legitimidad del modelo profesional descrito en la primera parte de este artículo. También se ha sugerido que la construcción de la frontera norte y de la lucha contra el terrorismo y otros problemas de seguridad doméstica, podían ser intentos por plantear nuevas hipótesis de conflicto que restablecieran la funcionalidad amagada del modelo vigente.

A pesar de un cierto éxito en convencer a la opinión pública respecto al "inminente"peligro colombiano (peligro, que en este caso no surge de la voluntad convencionalmente agresiva del Estado colombiano, sino de su incapacidad para implantar su pleno control geopolítico interno), resulta claro que las relaciones del sector público civil con las FFAA han seguido aguas convencionales; parece también claro que el modelo de fuerzas armadas basado en la idea de la modernización autonomista y rol-expansiva, se halla sometido a serias tensiones y fisuras.

Durante los últimos cinco años se han acumulado indicios de que este modelo profesional se puede desmoronar y que ha sufrido serios quebrantos. El modelo vigente está asentado, como se ha dicho antes, en la idea de la mutua abstención civil-militar, salvo en casos en que las fuerzas son llamadas a actuar en su papel de última instancia paraconstitucional. Al mismo tiempo se enraizaba en la preservación de un ámbito castrense más o menos inmune a la política civil y a sus dinámicas clientelares y caudillistas y a la búsqueda de un desarrollo institucional basado en normas burocráticas de corte "weberiano".

A lo largo del período 1979-2003, las FFAA o sus miembros han intervenido repetidamente en la vida política. Los motines y rebelio- 
nes de oficiales de mediana y baja graduación han ocurrido periódicamente y recurrentemente. Debe tenerse presente que ya en la década 1980, el General Frank Vargas Pazzos y sus leales pusieron en jaque al sistema democrático-representativo y que por tanto, la rebelión de enero de 2000 no necesita ir tan atrás como la Revolución Juliana para hallar antecedentes y analogías.

Debe pues diferenciarse netamente entre dos tipos o formas de pronunciamiento militar: a) el "institucional", donde el Alto Mando y los comandantes de fuerza toman una decisión de intervenir en nombre de las FFAA como conjunto y desde una perspectiva que hemos llamado paraconstitucional, y b) las rebeliones "tenentistas" de oficiales más jóvenes que actúan con un grado de independencia relativa frente a los Altos Mandos y a veces contra ellos. Este golpismo o insubordinación de oficiales más jóvenes puede o no darse en connivencia con facciones civiles, pero en todo caso, opera por canales extrareglamentarios y contra la disciplina y verticalidad del mando.

Golpes de Alto Mando, más propiamente descritos como "pronunciamientos", son los de 1963, 1972, 1976, 1996 y 2000 (la carta del Alto Mando conminando al Presidente Jamil Mahuad a abandonar su cargo) mientras que los de tipo "tenentista"se dan en 1925 (Revolución Juliana), 1944, 1986/87 y 2000 (la "toma"de edificios públicos por parte de los coroneles rebeldes y sus aliados civiles e indígenas).

Se ha señalado previamente que los "pronunciamientos" del Alto Mando pueden considerarse como parte "normal" (aunque no autoconsciente) de la institucionalidad "real" del Ecuador. Se ha dicho que los Altos Mandos juegan de hecho el rol de última instancia soberana provisional, en ausencia de un equivalente a los poderes últimos de los estados absolutistas o republicanos. Sin embargo, ¿qué hay de los motines "tenentistas"? Estos aparentemente son síntomas inequívocos del quiebre de la disciplina castrense y de la desintegración de la organización legal-burocrática que

\footnotetext{
'Término usado en Brasil para bautizar a las rebeliones de "Tenientes" que sacudieron a ese país en la década de 1920 y que hizo fortuna como palabra genérica usada para describir un fenómeno muy difundido en dicha década y en la siguiente en otros países de la región como Chile, Ecuador, Bolivia, Cuba etc.
} 
sostiene a dicha disciplina. Es difícil eludir la idea de que personajes como Frank Vargas Pazzos, Lucio Gutiérrez o los oficiales julianos estaban (al margen de los méritos sustantivos de sus propuestas) erosionando y destruyendo el profesionalismo militar y los valores republicanos de una fuerza militar moderna.

Antes de llegar a tal conclusión sería preciso, sin embargo, dar un paso atrás y preguntarse si no será posible hacer una reflexión similar en el caso de los motines que la que se hizo en el caso de los "pronunciamientos". En efecto, se notó que estas últimas formas de intervención militar obedecen a un patrón regular y sistemático. Se observó también que operan de acuerdo a procedimientos y prácticas regulares y en general repetitivas. Finalmente se constató que estas formas de intervención cumplen ciertas funciones muy precisas dentro del sistema político ecuatoriano.

¿No sería posible pensar otro tanto de las rebeliones "tenentistas'? Después de todo, ellas parecen seguir también un patrón recurrente, repetitivo y contar con una base de legitimidad implícita no despreciable. Después de todo, los oficiales involucrados casi siempre han contado con una base de apoyo popular importante, han podido a menudo hallar fuerte respaldo en grupos civiles y políticos relevantes y en ocasiones, sus líderes han sido "premiados" por los electores con carreras políticas prestantes. El caso del Presidente Lucio Gutiérrez no es para nada único, aunque sí el más connotado. El General Frank Vargas Pazzos, los oficiales julianos, los comandantes que manejaron la caída del Presidente Abdalá Bucaram, han sido personajes populares y han logrado ganar elecciones o competir como fuere candidatos en varias de ellas. En muchos casos, han sido luego fundadores de importantes partidos políticos tales como el Socialista, por citar solo un ejemplo².

Nos permitimos sugerir una hipótesis: el "golpe" de mandos medios es tan institucional como el de los Altos Mandos. Sin embargo, lo es de otra manera y con otra función. A esta podríamos bautizarla como la función "tribunicia"que en algunos sistemas cons-

2 Podríamos ir aún más lejos: ¿qué es el liberalismo posterior a Alfaro, sino el resultado de la intervención política de los militares "montoneros" de la revolución de 1895? 
titucionales ha sido contemplada como parte de la institucionalidad de los Estados.

La función tribunicia desarrolla una magistratura, que, al igual que la soberanía de última instancia opera como mecanismo de excepción, o al menos como recurso de enmienda de anomalías generadas al nivel de la gestión pública rutinaria.

El poder tribunicio, en general, se halla presente en sistemas sociales y políticos fuertemente estamentales y basados en relaciones clientelares. Opera como una válvula de seguridad ante asimetrías demasiado evidentes y masivas, y ante las dificultades de los sistemas clientelares para alcanzar universalismo y generalizada cobertura. Los sistemas de tribunos plebeyos revisten muchas formas, pero todas ellas tienen la forma de una especie de procuraduría de los más débiles, con poderes correctivos sobre el sistema político, poderes que, por otra parte, pueden ser muy amplios y representar casi un veto sobre el poderoso acusado de abusos.

Existen en los sistemas políticos premodernos un conjunto de funcionarios que cumplen labores vinculadas a la defensa de los fueros o del estatuto de la plebe y de los humildes, así como de asegurarse que la moralidad cívica de los poderosos no se aparte en exceso de la aceptable por parte de los grupos subordinados. En otras palabras, el funcionario tribunicio opera como una especie de garante de la mínima consistencia entre el poder y sus moralidades, por un lado, y el derecho estamental del común. En el Ecuador absolutista, el "protector de naturales"cumplía algunas funciones tribunicias.

En las repúblicas democráticas de corte moderno, las funciones tribunicias son asignadas a la judicatura y a funcionarios judiciales. Esto no puede ser conseguido en los sistemas de tipo "ancien regime" debido a que en ellos, jueces y fiscales son vistos como "agentes de la corona". su misión es defender los intereses del Estado, entendido este como el Gobierno, la dinastía, el príncipe y su aparato político. Mal pueden en estas condiciones los sistemas judiciales tomar el partido del común contra el Estado. A diferencia de los estados absolutistas, los de tipo republicano democrático ponen a los jueces como instancias imparciales entre los litigantes, 
incluido en esta categoría el propio Gobierno, que en sus tratos o disputas frente a los particulares debe ser visto como otro particular más.

De hecho, la imposibilidad de usar la judicatura como instancia de reparación de agravios del poder o de los poderosos ya apunta a que el Estado en cuestión sigue teniendo un "alma" absolutista o no ha logrado desarrollar una fuerte institucionalidad republicana (más allá de cualquier formalidad).

En estos Estados, es preciso retener la función tribunicia y mantener agentes o grupos que operen la compensación a las asimetrías de poder civiles y gubernamentales. Podemos sostener que la función tribunicia es aún necesaria en un sistema como el ecuatoriano, donde las líneas de quiebre del clientelismo, la falta de personería del común frente al Estado, las enormes asimetrías socio-económicas y culturales y las diferenciales de poder y recursos, se asemejan más a las propias de los estados prerevolucionarios que a las republicas capitalistas modernas.

Si esto es así y observando la recurrencia de los "golpes" de protesta conducidos por oficiales predominantemente de mediana graduación o de altos oficiales, al margen de los Altos Mandos, cabría preguntarse si esta repetición cíclica no obedece asimismo a una solapada institucionalización de la función tribunicia en las FFAA.

De esta forma los militares ecuatorianos no solo que tendrían la función para-constitucional de árbitro final de la política, sino que el amotinamiento de coroneles sería parte de un acuerdo tácitamente aceptado que les daría este papel de "abogados de la ple$b e$ "cuando el extrañamiento y la divergencia entre esta y los poderes fácticos civiles llega a extremos que violan un sentido tácito mínimo de equidad y de justicia sustantiva.

Sin embargo, esta putativa función no se daría de manera indiferenciada. Por seguir una metáfora parlamentaria, el Alto Mando operaría como una especie de cámara "alta"de seniors (senadores) con una finalidad estabilizadora de última instancia. Por su parte la oficialidad más joven funcionaría como una cámara de re- 
presentantes de última instancia o asamblea putativamente representativa del común (más que de la soberanía estatal, que en un régimen de tipo absolutista no se confunde con la voluntad del pueblo, la cual se opone como alteridad a la del principado o soberano).

De esta forma, la organización institucional de las FFAA silenciosamente duplicaría el sistema de pesos y contrapesos corporativista (no constitucional) que conforma el estado civil. Sería una especie de sombra militar del cuerpo político civil, pero que operaría como un duplicado o palimpsesto del orden de poderes constitucionales. Las FFAA proveerían pues de dos poderes adicionales al sistema político ecuatoriano: el poder moderador/arbitra/y el poder tribunicio o de representación (entendida la representación en un sentido no electoral).

A la luz de la anterior consideración, podría volverse sobre el tema de la quiebra del profesionalismo militar strictu senso, sobre todo a partir del año 2000 y de las políticas militares que se insinúan desde la toma del mando por parte del Presidente Lucio Gutiérrez.

Si lo anterior puede sostenerse, entonces, los oficiales del 21 de Enero, y el Coronel Lucio Gutiérrez no habrían actuado de manera extrasistémica. De hecho, las percepciones públicas contemporáneas no son de horror frente a una obvia ruptura del texto ostensible de la Constitución. Por el contrario, el golpe de Estado de enero de 2000, fue apoyado por algunos y aceptado por otros, pero repudiado por muy pocos, y tan solo rechazado por las clases medias urbanas, debido a la asociación de los amotinados con las organizaciones indígenas, lo cual desató ancestrales temores y fantasmas.

De hecho, en enero de 2000 se dieron dos acciones simultáneas y articuladas: la del Alto Mando en ejercicio de sus atribuciones arbitrales que implican una orden de disolución del Gobierno, junto con una "representación" comicial de los oficiales "junior" en subsidio y con apoyo del común (en este caso expresado en las organizaciones indígenas). De esta forma, en realidad, nadie tomó nunca en serio la supuesta pretensión de los amotinados por hacerse del poder. Probablemente ni los efímeros triunviros creyeron 
en ello. Su acción tenía como objeto hacer presente el descontento y la impaciencia del común frente a las reales o supuestas iniquidades del gobierno en ejercicio.

Es interesante ver la enorme tolerancia de la opinión pública y, en definitiva, del Estado hacia un grupo de oficiales que técnicamente y en estricto sentido legal habían cometido algunos de los más graves actos de indisciplina que un oficial de carrera puede cometer. Es que en realidad su acción no es vista como extraña a su función político-mortal, sino por el contrario, como parte del cumplimiento de su deber consuetudinario, como parte de un derecho sumergido que opera a espaldas y por debajo del ostensible y proclamado en las leyes formales.

De esta forma, podríamos sostener que Lucio Gutiérrez y sus colegas, cumplieron con el deber esperado de ellos, y como resultado, fueron amnistiados (se les dio el "visto bueno" político) y luego, llevados al poder bajo la cobertura de la Sociedad Patriótica por ellos fundada.

\section{¿QUÉ ES ENTONCES LO QUE HACE CRISIS EN LAS FFAA A PARTIR DEL AÑO 2000?}

Creemos que lo que se deteriora en realidad, es una autoimagen profesional y una coexistencia entre las funciones militares sumergidas y las manifiestas. El sistema que hemos intentado describir, aunque no consistente con la descripción formal que hacemos del rol profesional de las FFAA, al menos desde los cánones democrático-republicanos, es después de todo una institucionalidad y representa una cierta forma de universalismo estatal. No el universalismo que hemos querido creer real, no el universalismo de nuestra cultura libresca. Se trata más bien de un orden ético que, aunque de manera subrepticia, tiene una realidad efectiva en las prácticas de los sujetos, y en ese sentido es más real que nuestras concepciones idealizadas o que el voluntarismo de las elites cultas.

El problema que se le plantea a la institucionalidad militar desde 1998 y tal vez más marcadamente desde enero del 2000, es la posibilidad de que este orden se vea descompuesto desde otras formas de orden que no son propiamente estatales. 
Sea bajo su forma canónica de profesionalismo moderno, sea bajo las formas inconfesas de la institucionalidad sumergida, las FFAA del Ecuador han desarrollado un sistema organizacional que, al menos desde 1941, había apuntado a protegerse y aislarse de las instituciones dominantes de la sociedad civil, precisamente para poder... mejor su autonomía operacional frente a ellas. Estas instituciones dominantes han sido la familia extensa y la clientela (por otra parte, extensión generalizada de la racionalidad de la familia: "familia extensa simbólica", "mafia"). Si algo las FFAA han buscado neutralizar en su seno ha sido la acción disolvente de la razón nepotista.

La posible destrucción de este sistema de barreras laboriosamente construida, pone en peligro precisamente la subsistencia misma de un orden en que las FFAA pueden actuar desde su propia lógica sobre un mundo civil diferenciado de ellas. Si la lógica familística se extiende al seno de los cuarteles, y se hace posible desarrollar clientelas desde y en su interior, todo un siglo de desarrollo profesional se vendría al traste y nos veríamos retrotraídos al punto inicial del desarrollo profesional castrense: estaríamos de vuelta al momento de los "señores de la guerra", de los ejércitos de caudillo, al momento de los "condottieros", al mundo "floreano", del ejército patrimonialista, propiedad del caudillo.

La aniquilación del sistema profesional e institucional real de las Fuerzas Armadas nos retrotraería a una política pura y desnudamente maquiavélica, donde la subjetividad del poder hallaría su máximo y devendría en arbitrariedad solo limitada por las lógicas del linaje, de la reciprocidad y por la economía moral de la gratitud y la retribución.

Semejante perspectiva, por lo demás, no ha sido ajena al desarrollo político del país. Más de una gran transformación política del Ecuador ha tenido como uno de sus contenidos latentes más fuertes la sucesión (en un sentido casi Paretiano) de las elites y la renovación demográfica y social de las capas dominantes. No otra cosa estuvo agazapada detrás de los sucesivos advenimientos caudillistas. Cada uno de ellos ha tenido el impacto de operar un gran movimiento de convección social que ha levantado hasta la condición de miembros "bona fide" del poder a grupos hasta en- 
tonces marginados o marginales a este poder. Este proceso se dio a raíz de la secesión imperial de 1809-23, bajo el sistema floreano, bajo los caudillos y señores de la guerra de 1830-60, bajo Veintimilla, a raíz de la revolución liberal, a consecuencias del proceso juliano, con el velasquismo y con las dinastías populistas del CFPPRE.

Es posible, que estemos asistiendo a un nuevo capítulo de esta historia de revoluciones conservadoras, que consisten ante todo en la renovación de las elites por infusión de nuevas capas en su seno. Lo que constatamos es que la carrera de las armas y el militarismo, han sido siempre uno de los caminos privilegiados en esta renovación de los estratos dirigentes. Renovación que por otra parte sirve para repristinar la legitimidad del sistema estamental y el sistema de diferencia/deferencia. Esta movilidad valida la posibilidad de una movilidad social que no es individual, sino que se produce por movimientos de grupos y familias completos hacia la cúpula social. Las FFAA han sido, en el sistema clientelar, el punto de fuga que abre las puertas fuertemente cerradas de la jerarquía basada en el status, a nuevos linajes y grupos socio-culturales y es posible que todavía puedan hacer ese papel, como lo hicieron con los Flores, los Urbina, los Veintimilla, los Plaza o los Bowen. Pero, el precio a pagar ha sido, casi siempre, la destrucción o deterioro del sistema institucional y del profesionalismo militar, aun si lo entendemos fuera de los cánones democrático-republicanos clásicos. 
